\title{
The number of intestinal bacteria is not critical for the enhancement of antitumor activity and reduction of intestinal toxicity of irinotecan by the Chinese herbal medicine PHY906 (KD018)
}

\author{
Wing Lam ${ }^{1 \dagger}$, Zaoli Jiang ${ }^{1 \dagger}$, Fulan Guan ${ }^{1 \dagger}$, Rong Hu', Shwu-Huey Liu', Edward Chu ${ }^{2}$ and Yung-Chi Cheng ${ }^{1 *}$
}

\begin{abstract}
Background: The four-herb Chinese medicine PHY906(KD018) has been shown to both enhance the in vivo antitumor activity of irinotecan (CPT-11) against colon cancer tumor allografts and alleviate intestinal toxicity caused by CPT-11.

Methods: Since intestinal bacteria can metabolize CPT-11 and PHY906, we investigated whether intestinal bacteria play a critical role in the in vivo activity of PHY906 in murine Colon-38 tumor-bearing mice. Intestinal bacteria were depleted using streptomycin/neomycin for 10 days before and during treatment with PHY906 and/or CPT-11. qPCR using 165 DNA group-specific primers was used to quantify the levels of the major intestinal bacteria.

Results: Both PHY906 and antibiotic treatment changed the profile of intestinal bacteria species: Lactobacillus/ Enterococcus, Bacteroides, Clostridium leptum, and E. rectale/C. coccoides. Antibiotic treatment did not alter the ability of PHY906 to enhance the antitumor activity of CPT-11. Antibiotic treatment alone partially reduced animal body weight loss in CPT-11-treated mice. However, PHY906 treatment was able to protect against the body weight loss in the CPT-11/antibiotic treatment group. H\&E and PCNA staining of intestine showed that antibiotic treatment partially reduced the intestinal damage caused by CPT-11 but not as effectively as PHY906 treatment. Antibiotic treatment plus PHY906 conferred the most effective protection of intestine histological structure against damage by CPT-11. Both PHY906 and antibiotic treatment inhibited CPT-11-associated inflammatory processes, including infiltration of the intestine by neutrophils, MCP1 and TNF-alpha mRNA expression in the intestine, and expression of pro-inflammatory cytokines G-CSF and MCP1 proteins in the plasma. However, whereas antibiotic treatment suppressed the mRNA expression of two important intestinal progenitor/stem cell markers, Olfm4 and Lgr5, PHY906 treatment resulted in enhanced expression of these two stem cell markers.

Conclusions: Alterations in the population of intestinal bacteria did not affect the abilities of PHY906 to enhance CPT-11 antitumor activity or reduce the intestinal toxicity associated with CPT-11 treatment. The major species of intestinal bacteria do not appear to play a role in PHY906's enhancement of the therapeutic index of CPT-11 in tumor-bearing mice. Thus, patients with different intestinal bacterial profiles may still benefit from PHY906 treatment alongside CPT-11.
\end{abstract}

\footnotetext{
* Correspondence: ycccheng@yale.edu

${ }^{\dagger}$ Equal contributors

'Department of Pharmacology, Yale University School of Medicine, New

Haven, CT 06510, USA

Full list of author information is available at the end of the article
}

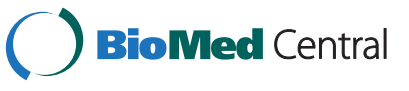

(C) 2014 Lam et al.; licensee BioMed Central. This is an Open Access article distributed under the terms of the Creative Commons Attribution License (http://creativecommons.org/licenses/by/4.0), which permits unrestricted use, distribution, and reproduction in any medium, provided the original work is properly credited. The Creative Commons Public Domain Dedication waiver (http://creativecommons.org/publicdomain/zero/1.0/) applies to the data made available in this article unless otherwise stated. 


\section{Background}

PHY906 (KD018) is based on the formulation Huang Qin Tang (HQT), which consists of four main herbs: Glycyrrhiza uralensis Fisch (G), Paeonia lactiflora Pall (P), Scutellaria baicalensis Georgi (S), and Ziziphus jujuba Mill (Z). Huang Qin Tang has been used for over 1800 years to treat a variety of gastrointestinal symptoms including diarrhea, nausea and vomiting, and abdominal cramps. PHY906 is manufactured using high-quality herbs picked by experienced herbalists and manufactured following cGMP (current Good Manufacturing Practice). Consistent preparations of PHY906 have been made over a period of 10 years as documented by Phytomics QC using standardized chemical and biological fingerprints [1].

Irinotecan (CPT-11) in combination with 5-fluorouracil (5-FU) and leucovorin continues to be used as the firstline therapy for treatment of metastatic colorectal cancer (mCRC). CPT-11 is also approved as a second-line monotherapy for recurrent $\mathrm{mCRC}$ following treatment with an oxaliplatin-based regimen. The dose-limiting toxicities of CPT-11 include nausea and vomiting, abdominal pain/cramps, and diarrhea. CPT-11 administration has also been shown to cause gastrointestinal bleeding, a symptom often associated with colonic ulceration resulting from intestinal cell death and inflammation (3). Once CPT-11 is administrated, it is converted to the active metabolite SN-38 (7-Ethyl-10-hydroxy-camptothecin) by hepatic and intestinal carboxyesterases [2-4]. SN-38 damages DNA in intestinal cells as well as tumor cells, and can trigger acute life-threatening diarrhea in patients [5]. In the liver, SN-38 is metabolized by hepatic UDP-glucuronyltransferase into the inactive SN-38G metabolite, which is excreted into the jejunum via the bile duct $[6,7]$. Intestinal bacterial $\beta$-glucuronidase can convert SN-38G back into the $\mathrm{SN}-38$ metabolite, which can directly damage the intestine and promote intestinal inflammation. Several approaches have been used to reduce GI toxicity resulting from CPT-11-based chemotherapy, including modification of the schedule of administration [8,9], intestinal alkalization $[10,11]$, treatment with anti-diarrheal therapies [12-16], genetic testing [17], ABCB1 transporter inhibitor treatment $[18,19]$, treatment with enzyme ( $\beta$-glucuronidase, UGT1A1, carboxylesterase, COX-2) inducers or inhibitors [20-23], antibiotic treatment [24-26], treatment with adsorbing agents [27,28], and treatment with other agents [29-32]. However, to date, none of these approaches has been found to be of significant clinical benefit.

Since Huang Qin Tang has been used for over 1800 years ago to treat diarrhea, PHY906 was chosen as a potential treatment strategy to reduce the GI side effects associated with CPT-11 treatment. In in vivo pre-clinical studies, PHY906 reduced the GI toxicities caused by CPT11 while simultaneously enhancing CPT-11's in vivo antitumor activity [33]. Each of the four main herbs comprising the PHY906 formula was required to maximize both its cytoprotective and antitumor effects. A phase 1/2 randomized double-blinded, placebo-controlled clinical trial was conducted to examine PHY906's clinical potential as an adjuvant to CPT-11, 5-fluorouracil, and leucovorin (5FU/LV) for the treatment of chemotherapy-naive mCRC patients. PHY906 treatment resulted in a significant decrease in the incidence of nausea/vomiting and diarrhea, and of note, treatment with PHY906 was not associated with any toxicity on its own $[34,35]$. The pharmacokinetics of CPT-11 and 5FU, respectively, was not affected by PHY906 treatment [34].

PHY906 is orally administrated, and the individual herbal components can be metabolized and transformed by gut flora. Individuals may carry different profiles of intestinal bacteria in their GI system depending on gender [36], diet [37], age [38], and co-morbid illnesses [38,39]. Therefore, the impact of PHY906 may be different for individuals with different spectra of intestinal flora. To test this hypothesis, we investigated the potential interaction of PHY906 and CPT-11 on intestinal damage and antitumor activity in mice with or without depletion of intestinal bacteria. Our findings demonstrate that the ability of PHY906 to increase the therapeutic index of PHY906 is not affected by levels of major bacteria species in the intestine.

\section{Methods}

Murine Colon-38 cells were transplanted subcutaneously into four- to six-week-old female BDF1 mice (Charles River Laboratories, Wilmington, MA). After 10 to 14 days, mice with tumor sizes of $150-300 \mathrm{~mm}^{3}$ were selected. Intestinal bacteria were depleted using streptomycin/neomycin $(200 \mathrm{mg} / \mathrm{kg}$, p.o. bid) for 10 days before and during the treatment of PHY906 and/or CPT-11. PHY906 was given orally (p.o.) for four days (twice per day; b.i.d., $500 \mathrm{mg} / \mathrm{kg})$ and CPT-11 (360 mg/kg) was administered intraperitioneally (i.p.) on day 0. On day 0, PHY906 was given 30 minutes prior to CPT-11 administration. Mice (BDF1 bearing Colon-38 tumors) were terminated by cervical dislocation on day 4 . Total DNA of the middle jejunum and the colon were purified using DNeasy Blood \& Tissue Kit (Qiagen, Germantown, MD) according to manufacturer's instructions. qPCR using 16S DNA groupspecific primers for Eubacteria, Lactobacillus/Enterococcus group (Lact), Bacteroides group (Bact), Clostridium leptum group (Clept) and E. rectale/C. coccoides group (Erec) was used to quantify the major intestinal bacteria in the middle jejunum and the colon [40]. Middle jejunum tissues were removed, fixed in formalin, embedded in paraffin, and sectioned into $10 \mu \mathrm{m}$ pieces. Immunohistochemistry was used to detect protein expression in the middle jejunum tissues. Apoptosis was quantified by cleaved caspase 
3 staining [33]. Cell proliferation was determined by proliferating cell nuclear antigen (PCNA) staining [33]. Quantitative RT real-time PCR was used to quantify Lgr5, Olfm4, Bmi, TNF $\alpha$, and MCP1 mRNA expression in the middle jejunum [33]. Cytokine expression in the plasma was measured using the $\mathrm{BD}^{\mathrm{TM}} \mathrm{CBA}$ (Cytometric Bead Array) (BD biosciences, San Jose, CA) according to manufacturer's instructions [33]. Data were analyzed by one-way or two-way ANOVA (GraphPad Prism 5, San Diego, CA), Student's T-test (Microsoft Office Excel), and correlation analysis (GraphPad Prism 4). Difference were considered to be statistically significant when $\mathrm{P}<0.05$. All animal experiments were carried out in accordance with an approved Yale University Institutional Animal Care and Use Committee (IACUC) protocol. Murine Colon 38 cell lines were provided by Dr. Giuseppe Pizzorno, Ph.D., Pharm.D (Translational Science, Nevada Cancer Institute, USA).

\section{Results}

Treatment with PHY906, antibiotics, and/or CPT-11 alters the profile of major intestinal bacteria species

Intestinal bacteria in Colon-38 tumor bearing BDF1 mice was depleted with streptomycin/neomycin $(200 \mathrm{mg} / \mathrm{kg}$, p.o. bid) for 10 days before (our preliminary result indicated 7-day pre-treatment was not sufficient to deplete intestinal bacteria, data not shown) treatment with PHY906 (500 mg, p.o. bid days 0-3) and/or CPT-11 (360 mg/kg, I.P. day 0). On day 4, qPCR was used to quantify the levels of major intestinal bacteria in the middle jejunum and in the colon, using 16S DNA group-specific primers for $E u$ bacteria, Lactobacillus/Enterococcus group (Lact), Bacteroides group (Bact), Clostridium leptum group (Clept) and E. rectale/C. coccoides group (Erec). As seen in Figure 1, PHY906 treatment significantly decreased levels of Bact $(\mathrm{P}=0.012)$ and Erec $(\mathrm{P}=0.03)$ (Figure 1A, C, F) but caused a slight increase in Lact (Figure 1A, B). PHY906 treatment increased levels of Clept but not Lact, Bact, or Erec in the colon, and it had no effect on Clept levels in the middle jejunum (Figure 1A, I). CPT-11 treatment significantly reduced levels of Bact $(\mathrm{P}=0.014)$ and Erec $(\mathrm{P}=0.04)$ (Figure 1A, H, J) but not Lact or Clept in the middle jejunum. In the colon, CPT-11 increased the density of Lact $(\mathrm{P}=0.03)$ (Figure $1 \mathrm{~A}, \mathrm{G})$. Administration of PHY906 following CPT-11 treatment significantly increased levels of Clept $(P=0.04)$ and Erec $(P=0.03)$ (Figure 1A, I, J) but not Lact and Bact in the colon. In middle jejunum, PHY906 + CPT-11 treatment only increased the density of Erec $(P=0.03)$ (Figure 1A, F).

In the colon, antibiotic treatment depleted the density of Bact, Clept, and Erec by more than $99 \%$ but did not affect that of Lact (Figure 1A, G-J). In the middle jejunum, antibiotics reduced levels of Lact, Bact, and Clept by about $95 \%$ and decreased Erec by nearly $80 \%$
(Figure 1A-F). After antibiotic treatment, both PHY906 and CPT-11 increased the density of Erec $(P=0.02$ and 0.04, respectively) (Figure 1A, J) but not Lact, Bact, or Clept in the colon; antibiotic + drug treatment also had no effect on the levels of tested bacteria in the middle jejunum. It is interesting to note that treatment with CPT11, antibiotic, and PHY906 caused a significant increase in the density of Lact $(\mathrm{P}=0.004)$ (Figure $1 \mathrm{~A}, \mathrm{~B})$ in the middle jejunum but not the colon. The level of Lact in CPT11/PHY906/antibiotic-treated mice was nearly 10-fold higher $(\mathrm{P}=0.004)$ than that observed in the control group in antibiotic treatment conditions (Figure 1A, B).

Taken together, these studies show that PHY906 and CPT-11 with or without antibiotic treatment have variable effects on bacterial profiles in different regions of the intestine. Moreover, the interaction between PHY906 and CPT-11 could change bacterial profiles in the different segments of intestine.

\section{The effect of antibiotic treatment on the anti-tumor activities of CPT-11 and CPT-11/PHY906}

As it has been shown previously, treatment with PHY906 alone did not affect Colon-38 tumor growth. However, PHY906 was able to significantly enhance the antitumor activity of CPT-11 against Colon-38 cells $(\mathrm{P}<0.0083)$ (Figure 2A). Treatment with antibiotics alone did not alter Colon-38 tumor growth (Figure 2A). Furthermore, antibiotic treatment did not affect the antitumor activity of either PHY906 or CPT-11 (Figure 2A). Most importantly, antibiotic treatment had no effect on the ability of PHY906 to significantly enhance the antitumor activity of CPT-11 against Colon-38 tumor growth $(\mathrm{P}<0.0001)$. Cleaved caspase-3 staining indicated that PHY906 increased the level of apoptosis in Colon-38 tumors induced by CPT-11 with $(\mathrm{P}=0.014)$ or without $(\mathrm{P}=0.002)$ antibiotic treatment (Figure 2B, C).

\section{PHY906 reduced GI damage caused by CPT-11 regardless of antibiotic treatment}

PHY906 treatment did little to reverse the body weight loss caused by CPT- 11 by day 2 but promoted a significant recovery in body weight by day 4 (Figure $3 \mathrm{~A}$ ), a result consistent with our previous findings [33]. Antibiotic treatment partially mitigated the body weight loss triggered by CPT-11 between day 2 and day $4(\mathrm{P}=0.051)$ (Figure 3A). PHY906 further protected against CPT-11-triggered body weight loss regardless of antibiotic treatment (Figure 3A). There was no difference in animal body weight between the CPT-11/PHY906 group and the CPT-11/PHY906/ antibiotic group on day 4. (Figure 3A); PHY906 alone could significantly protect against body weight loss following CPT-11 treatment on day 4 (Figure 3A). In conclusion, PHY906 was able to enhance the antitumor activity of CPT11 and protect against CPT11-triggered body 


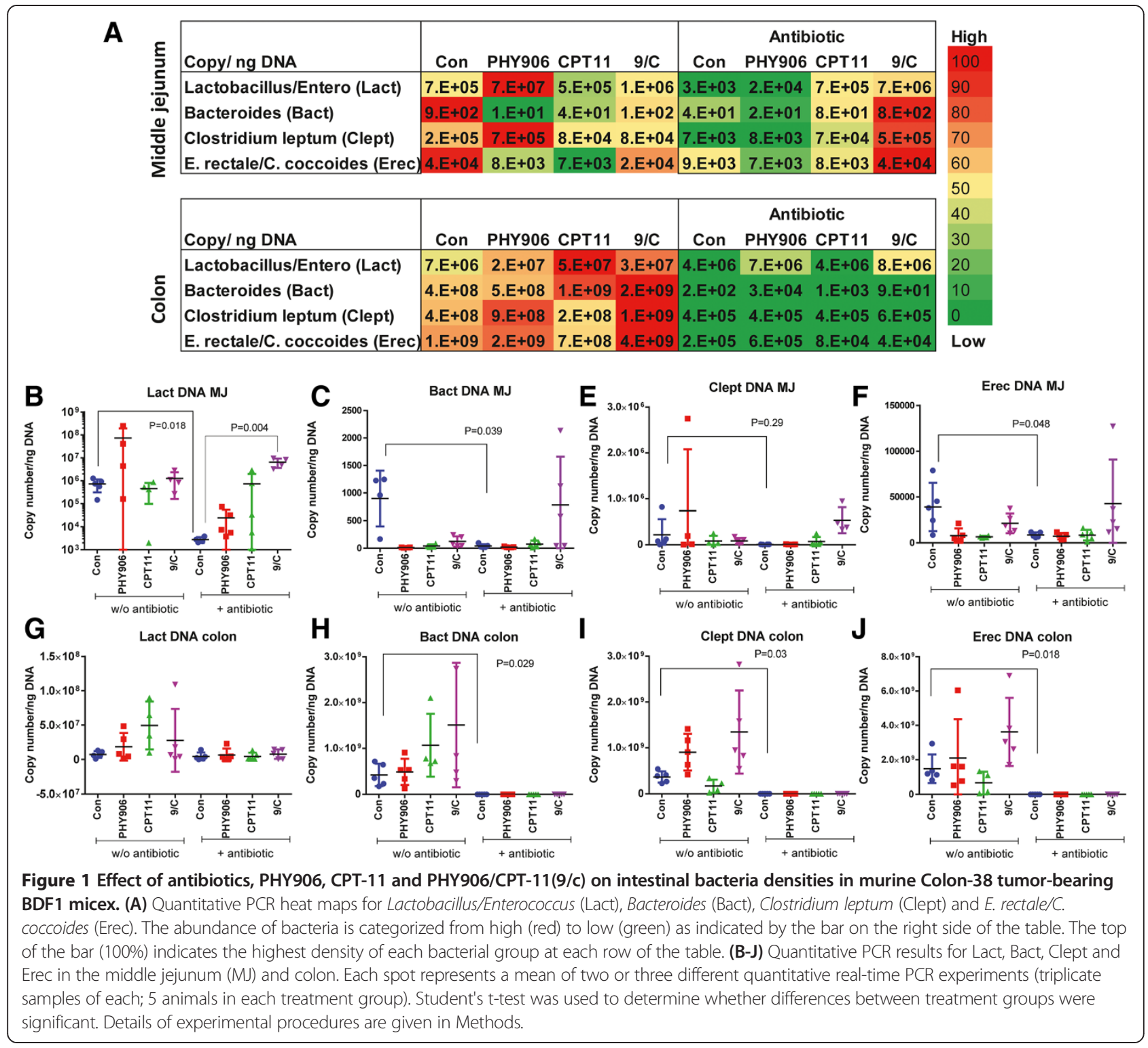

weight loss in mice with different intestinal bacteria profiles.

Consistent with our previous report [33], mice treated with CPT-11/PHY906 displayed improved histology in the middle jejunum, especially in the crypt area, as compared to mice treated with CPT-11 alone (Figure 3B). PCNA staining also indicated that the majority of GI crypt cells in mice treated with CPT-11/PHY906 were actively proliferating (Figure 3C). Antibiotic treatment was able to protect some crypts from damage caused by CPT-11 but was not nearly as effective as PHY906 treatment alone (Figure 3B). PCNA staining showed only some crypt cells actively proliferating in mice treated with antibiotics plus CPT-11 (Figure 3C). PHY906 plus antibiotic treatment yielded the most pronounced improvement in the histology of the middle jejunum from damage caused by CPT-11 (Figure 3B). However, RT-qPCR results indicated that antibiotic treatment could affect two important intestinal progenitor/stem cell markers: Lgr5 and Olfm4 mRNA expression. Antibiotic treatment alone strongly inhibited Lgr5 mRNA expression $(P=0.001)$ to a level similar to that in CPT-11-treated mice (Figure 3D). However, antibiotic treatment did not affect PHY906's induction of Lgr5 mRNA expression following CPT-11 treatment $(\mathrm{P}<0.0001)$ (Figure $3 \mathrm{D})$. Furthermore, although antibiotic treatment did not significantly inhibit Olfm4 or Bmi mRNA expression (Figure 3E, F), antibiotic treatment inhibited PHY906's induction of Olfm4 mRNA expression following CPT-11 treatment (Figure 3E). These results suggest that antibiotic treatment or the profile of intestinal bacteria may in some manner affect the behavior of intestinal progenitor/stem cells. 


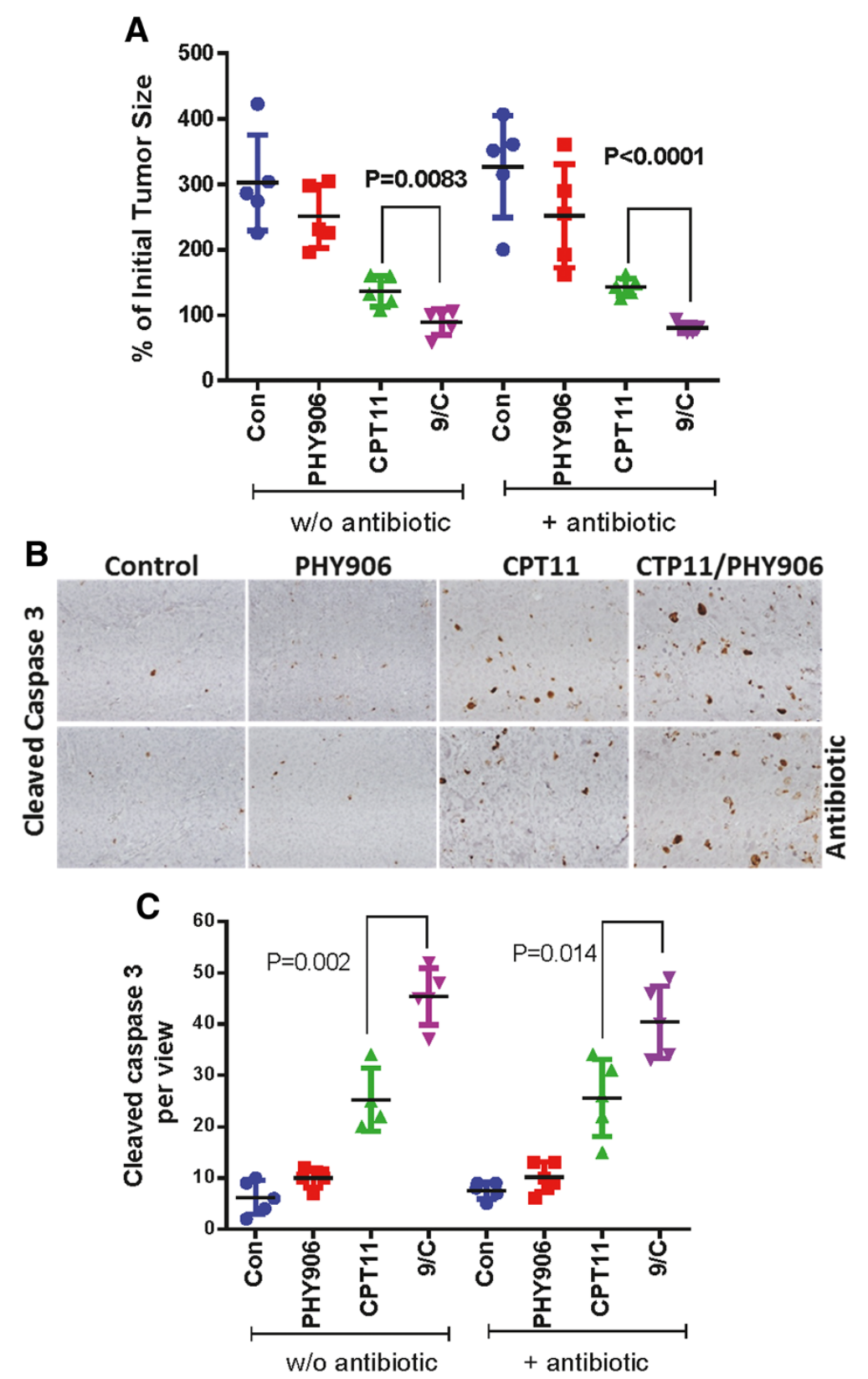

Figure 2 Effect of antibiotic treatment on the anti-tumor activity and GI toxicity of PHY906, CPT-11 and PHY906/CPT-11(9/c) in murine Colon-38 tumor-bearing BDF1 mice. (A) Effect of PHY906 and/or CPT-11 on the growth of Colon 38 tumor cells in BDF1 mice with or without (w/O) antibiotic treatment. Each spot represents an individual tumor's size relative to that at initial treatment. One way ANOVA was used to determine the significance of the differences between curves (B) Immunohistochemistry staining for cleaved caspase-3 in Colon-38 tumor sections under different treatment conditions as indicated on the graph. Photographs in the figure were taken at 200x magnification. (C) Quantitation of cleaved caspase-3 staining. Cleaved caspase-3 stained cell per each view of Colon-38 tumor sections following different treatment conditions as indicated on the graph. Each spot represents the mean number of heavily stained cells from 4 to 5 views of each tumor section. Student's t-test was used to determine whether differences between treatment groups were significant. Details of the experimental procedures are given in Methods.

Anti-inflammation activity of PHY906 against CPT-11 toxicity is not affected by antibiotic treatment As stated previously [33], PHY906 treatment inhibited several inflammatory processes triggered by CPT-11 in the middle jejunum, including neutrophil infiltration of the intestine (Figure 4A) and stimulation of TNF- $\alpha$ and
MCP1 mRNA expression (Figure 4B and C). In the plasma, PHY906 reduced expression of pro-inflammatory cytokines induced by CPT-11 such as MCP1, G-CSF, and IL6 (Figure 4D-F). Antibiotic treatment also exhibited substantial anti-inflammatory activity in CPT-11-treated animals. It should be noted that 10 -day pre-treatment 


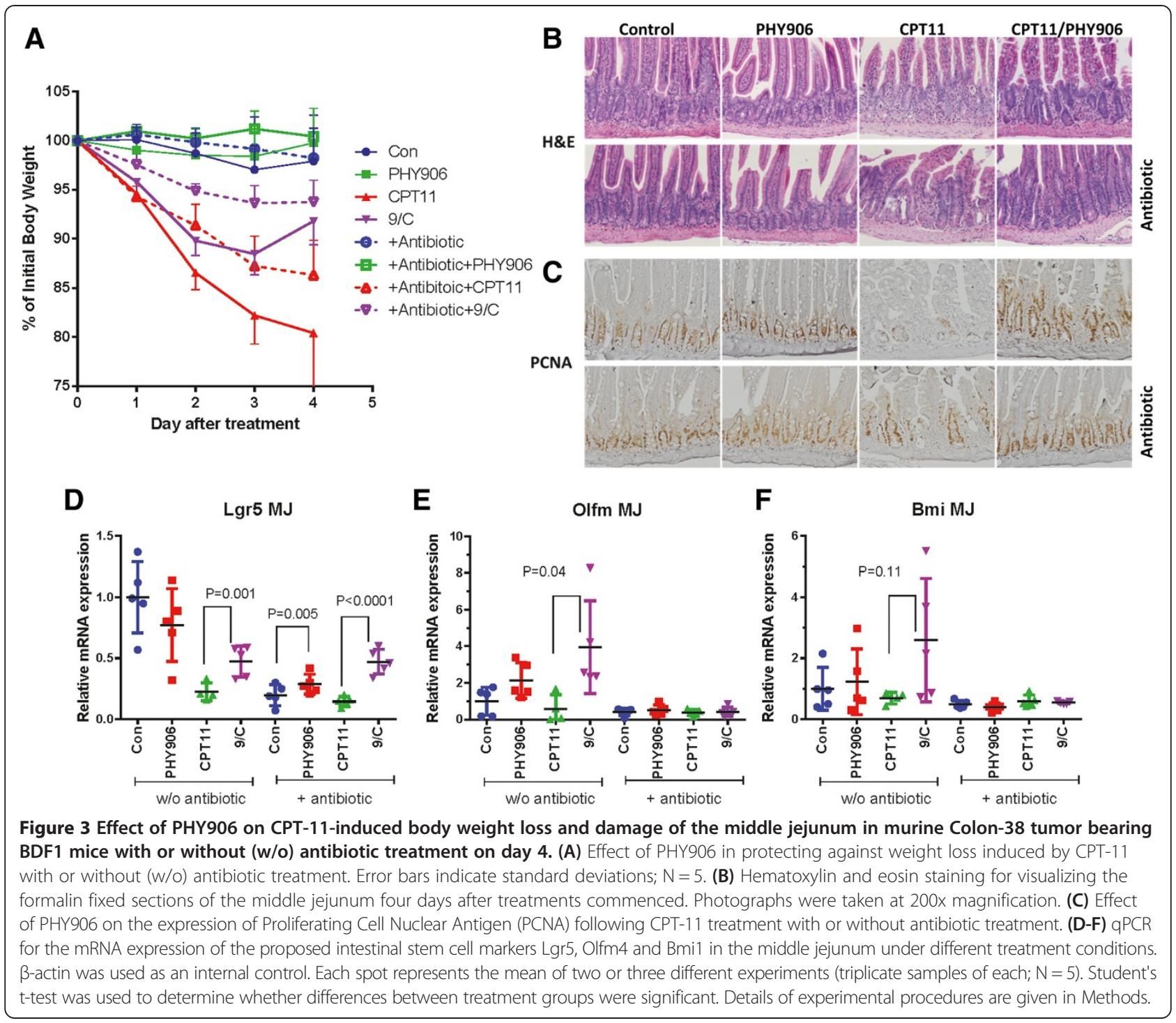

with antibiotic significantly lowered the basal level of intestinal inflammation as reflected by a reduction in TNF- $\alpha(\mathrm{P}=0.003)$ and MCP1 $(\mathrm{P}=0.01) \mathrm{mRNA}$ (Figure 4B and $\mathrm{C}$ ). However, antibiotic treatment did not affect basal levels of pro-inflammatory cytokines in the plasma.

\section{Discussion}

The Chinese herbal medicine Huang-Qin Tang has a nearly 2000-year history of use for treatment of GI side effects such as diarrhea, nausea, vomiting, and abdominal cramps. However, the direct effect of Huang-Qin Tang on intestinal bacteria levels has never been formally investigated. Herein, we investigated the ability of PHY906, a standardized cGMP "Huang-Qin Tang" equivalent, to alter bacterial profiles differently in different segments of intestine. Our in vivo studies have shown that PHY906 does not act as a broad-spectrum antibiotic against the bacteria that were tested in our studies. For example, PHY906 treatment only inhibited Bact and Erec while antibiotic treatment decreased all kinds of tested bacteria in the middle jejunum. Thus, the underlying mechanism of Huang-Qin Tang for the treatment of diarrhea is completely different from that of anti-diarrheal antibiotics. However, one caveat is that PHY906 might still have antibiotic activity against certain bacteria that were not tested in the present study. Indeed, several studies have reported that individual herbs of PHY906 possess antibiotic activity. Different Chemicals of Paeonia lactiflora were found to have different activities against Bact [41]. It was found that human intestinal bacteria could transform flavonoids of Scutellaria baicalensis into aglyconeflavonoids, baicalein, oroxylin A, wogonin and norwogonin, each of which has different potencies against different types of intestinal bacteria [42]. Glycyrrhizol A and 6,8-diisoprenyl-5,7,4'-trihydroxyisoflavone (5) isolated form Glycyrrhiza uralensis were shown to exhibit potent 


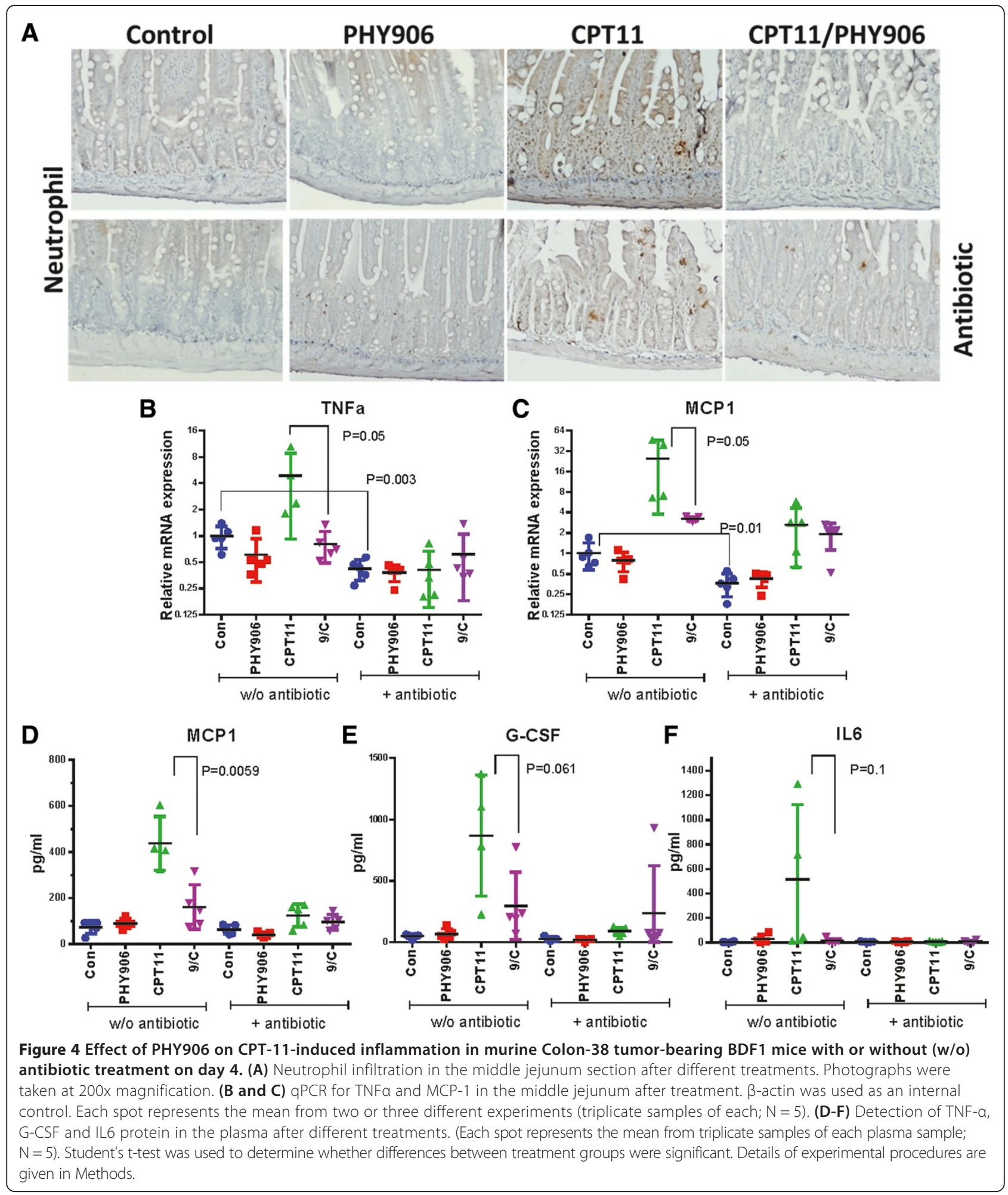

antibacterial activity against Streptococcus mutants [43]. Crude ethanol extracts of Ziziphus jujuba fruits were also reported to exhibit antibacterial activity [44]. Future investigations, such as a comparison of the impacts of different herbal combinations of PHY906 on intestinal bacterial profiles, could help us to address which herb(s) or chemical(s) are responsible for which of PHY906's antibiotic activities.

Previous studies have shown that treatment of PHY906 with $E$. coli $\beta$-glucuronidase alters the mixture's bioactivities. 
PHY906 treated with $\beta$-glucuronidase was found to exhibit stronger Wnt3a potentiation activity and anti-TNF $\alpha$ activity but weaker anti-iNOS activity in vitro [33]. Thus, using antibiotics to deplete intestine bacteria, which have high $\beta$-glucuronidase activity, would be expected to have an antagonistic effect on PHY906's biological activity. In addition, antibiotic treatment should also lead to reduced SN38 formation and damage of intestinal tissues. Streptomycin/neomycin treatment depleted over $90 \%$ of the major bacteria species in the gut. This finding is consistent with other reports in the literature [24,45]. We observed that antibiotic treatment partially protected intestinal tissue from CPT-11 toxicity without enhancing CPT-11's antitumor activity. In contrast, PHY906 was able to reduce the extent of GI damage while enhancing the antitumor activity of CPT-11. Thus, our studies suggest that PHY906 is able to maintain its biological activity in the presence of a wide range of intestinal bacteria and their respective $\beta$-glucuronidases. Perhaps human $\beta$ glucuronidase and UDP-glucuronosyltransferase (UGT), both of which are expressed in intestinal tissues, may impact PHY906 metabolism. In our phase I/ll clinical trial for treatment of mCRC patients, most plasma flavonoids from the orally administrated PHY906 were found to be glucuronidated, although some were sulfonated or methylated [46]. Our preliminary studies suggest that both human glucuronidase and UGT(s) play key roles in the metabolism of flavonoids in PHY906.

Treatment with either PHY906 or antibiotics may be able to reduce CPT-11-induced inflammation, including neutrophil infiltration of intestine, MCP1 and TNF- $\alpha$ mRNA expression in the intestine, and increased expression of pro-inflammatory cytokines G-CSF and MCP1 proteins in the plasma. However, it appears that PHY906 and antibiotics have different mechanism of action. It is known that intestinal bacteria are normally localized to the loose mucus and cannot penetrate the inner mucus layer [47-49]. However, damage to the mucus layer by CPT-11 allows intestinal bacteria to come in contact with epithelial cells or enter the blood stream, thus triggering the inflammatory process. Antibiotic treatment significantly reduces the level of intestinal bacteria and reduces the likelihood of bacteria-induced inflammation following CPT-11 treatment. This could also explain why antibiotic treatment alone reduced the basal level of MCP1 and TNF- $\alpha$ mRNA expression. In contrast, PHY906 accelerates the repopulation of epithelial cells, which restore the mucus layer and thus prevent bacterial penetration. PHY906 also suppresses inflammation by targeting several key signaling pathways, including NF-kB, iNOS, and COX2. For these reasons, the combination of antibiotics with PHY906 appears to more effectively suppress CPT11-triggered inflammation and preserve the intestinal histological structure than either component alone.
However, while antibiotic treatment did not affect PHY906's induction of Lgr5 expression, it did suppress expression of intestinal progenitor/stem cell markers and inhibit PHY906's ability to increase Olfm4 and Bmi levels following CPT-11 treatment. Lgr5 [50,51], Olfm4 [52], and Bmi [53] all play important roles in maintaining the growth of intestinal progenitor/stem cells in the crypts of different segments of the intestine; intestinal bacteria can thus modulate intestinal stem cell proliferation to maintain gut homeostasis via the JAK-STAT and JNK pathways as demonstrated in Drosophila [54]. Therefore, the combination of PHY906 and antibiotics may not be the optimal approach to protect intestinal tissues from damage caused by CPT-11 or other toxic agents.

Inflammatory bowel diseases (IBD), including ulcerative colitis and Crohn's disease, are caused by an innate immune response to luminal microflora in individuals with a certain genetic disposition. A recent finding indicated that the density of Clept is significantly reduced in the fecal microbiota of patients with Crohn's disease and ulcerative colitis [39]. Our results showed that PHY906 alone can increase the density of Clept in colonic tissue. PHY906 is also able to maintain Clept and Erec levels in the colon following CPT-11 treatment. Therefore, PHY906 may have potential benefit in treating IBD by restoring the density of Clept in the colon. In addition, PHY906 inhibits NF-kB, COX2, and iNOS, all of which play key roles in IBD [55-57]. Thus, the potential use of PHY906 in treating IBD is worthy of further investigation.

\section{Conclusions}

Our studies have shown that the depletion of intestinal bacteria by antibiotics does not impact the ability of PHY906 to enhance CPT-11's antitumor activity and to protect against $\mathrm{CPT}-11$-induced intestinal toxicity. $\mathrm{Pa}$ tients with a range of intestinal bacterial profiles may thus benefit from the use of PHY906 as a modulator of CPT-11-based treatment.

\section{Abbreviations}

CPT-11: Irinotecan; qPCR: Quantitative real-time polymerase chain reaction; RT-qPCR: Reverse transcription quantitative real-time polymerase chain reaction; Lact: Eubacteria, Lactobacillus/Enterococcus group; Bact: Bacteroides group; Clept: Clostridium leptum group; Erec: E. rectale/C. coccoides group; mCRC: metastatic colorectal cancer; GI: Gastrointestinal; cGMP: current Good Manufacturing Practice; G: Glycyrrhiza uralensis Fisch; P: Paeonia lactiflora Pall; S: Scutellaria baicalensis Georgi; Z: Ziziphus jujuba Mill; MCP1: Monocyte Chemoattractant Protein-1; G-CSF: Granulocyte colony stimulating factor; iNOS: Inducible nitric oxide synthase; IBD: Inflammatory bowel disease.

\section{Competing interests}

Yung-Chi Cheng and Shwu-Huey Liu are the co-inventors of PHY906 for cancer treatment. 


\section{Authors' contributions}

WL did GPCR, took immunohischemical staining photos, analyzed results and wrote the manuscript. ZJ did animal experiments. Fulan Guan did immunohistochemical staining. RH did GPCR. Shwu-Huey Liu provided PHY906 and discussed results. EC discussed results and wrote the manuscript. Y-CC designed experiments, analyzed results and wrote the manuscript. All authors read and approved the final manuscript.

\section{Acknowledgment}

This work was supported by the National Cancer Institute (NCI) (PO1CA154295-01A1), and from the National Center for Complementary and Alternative Medicine (NCCAM), NIH, USA. Yung-Chi Cheng is a fellow of the National Foundation for Cancer Research, USA.

\section{Author details}

${ }^{1}$ Department of Pharmacology, Yale University School of Medicine, New Haven, CT 06510, USA. ${ }^{2}$ University of Pittsburgh Cancer Institute, University of Pittsburgh School of Medicine, Pittsburgh, PA 15232, USA.

Received: 12 July 2014 Accepted: 11 December 2014 Published: 15 December 2014

\section{References}

1. Tilton R, Paiva AA, Guan JQ, Marathe R, Jiang Z, van Eyndhoven W, Bjoraker J, Prusoff Z, Wang H, Liu SH, Cheng YC: A comprehensive platform for quality control of botanical drugs (PhytomicsQC): a case study of Huangqin Tang (HQT) and PHY906. Chin Med 2010, 5:30.

2. Khanna R, Morton CL, Danks MK, Potter PM: Proficient metabolism of irinotecan by a human intestinal carboxylesterase. Cancer Res 2000, 60(17):4725-4728.

3. Morton CL, Wierdl M, Oliver L, Ma MK, Danks MK, Stewart CF, Eiseman JL, Potter PM: Activation of CPT-11 in mice: identification and analysis of a highly effective plasma esterase. Cancer Res 2000, 60(15):4206-4210.

4. Satoh T, Hosokawa M, Atsumi R, Suzuki W, Hakusui H, Nagai E: Metabolic activation of CPT-11, 7-ethyl-10-[4-(1-piperidino)-1piperidino]carbonyloxycamptothecin, a novel antitumor agent, by carboxylesterase. Biol Pharm Bull 1994, 17(5):662-664.

5. Ikuno N, Soda H, Watanabe M, Oka M: Irinotecan (CPT-11) and characteristic mucosal changes in the mouse ileum and cecum. J Nat/ Cancer Inst 1995, 87(24):1876-1883.

6. Rivory LP, Bowles MR, Robert J, Pond SM: Conversion of irinotecan (CPT-11) to its active metabolite, 7-ethyl-10-hydroxycamptothecin (SN-38), by human liver carboxylesterase. Biochem Pharmacol 1996, 52(7):1103-1111.

7. Humerickhouse R, Lohrbach K, Li L, Bosron WF, Dolan ME: Characterization of CPT-11 hydrolysis by human liver carboxylesterase isoforms hCE-1 and hCE-2. Cancer Res 2000, 60(5):1189-1192.

8. Takimoto CH, Morrison G, Harold N, Quinn M, Monahan BP, Band RA, Cottrell J, Guemei A, Llorens V, Hehman H, Ismail AS, Flemming D, Gosky DM, Hirota H, Berger SJ, Berger NA, Chen AP, Shapiro JD, Arbuck SG, Wright J, Hamilton JM, Allegra CJ, Grem JL: Phase I and pharmacologic study of irinotecan administered as a 96-hour infusion weekly to adult cancer patients. J Clin Oncol 2000, 18(3):659-667.

9. Herben VM, Schellens JH, Swart M, Gruia G, Vernillet L, Beijnen JH, ten Bokkel Huinink WW: Phase I and pharmacokinetic study of irinotecan administered as a low-dose, continuous intravenous infusion over 14 days in patients with malignant solid tumors. J Clin Oncol 1999, 17(6):1897-1905.

10. Valenti Moreno V, Brunet Vidal J, Manzano Alemany H, Salud Salvia A, Llobera Serentill M, Cabezas Montero I, Servitja Tormo S, Sopena Bert E, Guma Padro J: Prevention of irinotecan associated diarrhea by intestinal alkalization. A pilot study in gastrointestinal cancer patients. Clin Trans/ Oncol 2006, 8(3):208-212

11. Tamura T, Yasutake K, Nishisaki H, Nakashima T, Horita K, Hirohata S, Ishii A, Hamano K, Aoyama N, Shirasaka D, Kamigaki T, Kasuga M: Prevention of irinotecan-induced diarrhea by oral sodium bicarbonate and influence on pharmacokinetics. Oncology 2004, 67(5-6):327-337.

12. Benson AB 3rd, Ajani JA, Catalano RB, Engelking C, Kornblau SM, Martenson JA Jr, McCallum R, Mitchell EP, O'Dorisio TM, Vokes EE, Wadler S: Recommended guidelines for the treatment of cancer treatmentinduced diarrhea. J Clin Oncol 2004, 22(14):2918-2926.
13. Rosenoff $\mathrm{SH}$ : Octreotide LAR resolves severe chemotherapy-induced diarrhoea (CID) and allows continuation of full-dose therapy. Eur I Cancer Care (Engl) 2004, 13(4):380-383.

14. Ychou M, Douillard JY, Rougier P, Adenis A, Mousseau M, Dufour P, Wendling JL, Burki F, Mignard D, Marty M: Randomized comparison of prophylactic antidiarrheal treatment versus no prophylactic antidiarrheal treatment in patients receiving CPT-11 (irinotecan) for advanced 5-FU-resistant colorectal cancer: an open-label multicenter phase II study. Am J Clin Oncol 2000, 23(2):143-148.

15. Karthaus M, Ballo H, Abenhardt W, Steinmetz T, Geer T, Schimke J, Braumann D, Behrens R, Behringer D, Kindler M, Messmann H, Boeck HP, Greinwald R, Kleeberg U: Prospective, double-blind, placebo-controlled, multicenter, randomized phase III study with orally administered budesonide for prevention of irinotecan (CPT-11)-induced diarrhea in patients with advanced colorectal cancer. Oncology 2005, 68(4-6):326-332.

16. Duffour J, Gourgou S, Seitz JF, Senesse P, Boutet O, Castera D, Kramar A, Ychou M: Efficacy of prophylactic anti-diarrhoeal treatment in patients receiving Campto for advanced colorectal cancer. Anticancer Res 2002, 22(6B):3727-3731.

17. Evaluation of Genomic Applications in P, Prevention Working G: Recommendations from the EGAPP Working Group: can UGT1A1 genotyping reduce morbidity and mortality in patients with metastatic colorectal cancer treated with irinotecan? Genet Med 2009, 11(1):15-20.

18. Vasudev NS, Jagdev S, Anthoney DA, Seymour MT: Intravenous irinotecan plus oral ciclosporin. Clin Oncol 2005, 17(8):646-649.

19. Desai AA, Kindler HL, Taber D, Agamah E, Mani S, Wade-Oliver K, Ratain MJ, Vokes EE: Modulation of irinotecan with cyclosporine: a phase II trial in advanced colorectal cancer. Cancer Chemother Pharmacol 2005, 56(4):421-426.

20. Fakih MG, Rustum YM: Does celecoxib have a role in the treatment of patients with colorectal cancer? Clin Colorectal Cancer 2009, 8(1):11-14

21. Sakata Y, Suzuki H, Kamataki T: Preventive effect of TJ-14, a kampo (Chinese herb) medicine, on diarrhea induced by irinotecan hydrochloride (CPT-11) Gan to kagaku ryoho Cancer Chemother 1994, 21(8):1241-1244.

22. Mori $K$, Kondo T, Kamiyama Y, Kano Y, Tominaga K: Preventive effect of Kampo medicine (Hangeshashin-to) against irinotecan-induced diarrhea in advanced non-small-cell lung cancer. Cancer Chemother Pharmacol 2003, 51(5):403-406.

23. Tobin PJ, Beale P, Noney L, Liddell S, Rivory LP, Clarke S: A pilot study on the safety of combining chrysin, a non-absorbable inducer of UGT1A1, and irinotecan (CPT-11) to treat metastatic colorectal cancer. Cancer Chemother Pharmacol 2006, 57(3):309-316.

24. Kehrer DF, Sparreboom A, Verweij J, de Bruijn P, Nierop CA, van de Schraaf J, Ruijgrok EJ, de Jonge MJ: Modulation of irinotecan-induced diarrhea by cotreatment with neomycin in cancer patients. Clin Cancer Res 2001, 7(5):1136-1141.

25. Alimonti A, Satta F, Pavese I, Burattini E, Zoffoli V, Vecchione A: Prevention of irinotecan plus 5 -fluorouracil/leucovorin-induced diarrhoea by oral administration of neomycin plus bacitracin in first-line treatment of advanced colorectal cancer. Ann Oncol 2003, 14(5):805-806.

26. de Jong FA, Kehrer DF, Mathijssen RH, Creemers GJ, de Bruijn P, van Schaik RH, Planting AS, van der Gaast A, Eskens FA, Janssen JT, Ruit JB, Verweij J, Sparreboom A, de Jonge MJ: Prophylaxis of irinotecan-induced diarrhea with neomycin and potential role for UGT1A $1 * 28$ genotype screening: a doubleblind, randomized, placebo-controlled study. Oncologist 2006, 11(8):944-954.

27. Michael M, Brittain M, Nagai J, Feld R, Hedley D, Oza A, Siu L, Moore MJ: Phase II study of activated charcoal to prevent irinotecan-induced diarrhea. J Clin Oncol 2004, 22(21):4410-4417.

28. Sergio GC, Felix GM, Luis JV: Activated charcoal to prevent irinotecan-induced diarrhea in children. Pediatr Blood Cancer 2008, 51(1):49-52.

29. Govindarajan R: Irinotecan/thalidomide in metastatic colorectal cancer. Oncology (Williston Park) 2002, 16(4 Suppl 3):23-26.

30. Villalona-Calero M, Schaaf L, Phillips G, Otterson G, Panico K, Duan W, Kleiber B, Shah M, Young D, Wu WH, Kuhn J: Thalidomide and celecoxib as potential modulators of irinotecan's activity in cancer patients. Cancer Chemother Pharmacol 2007, 59(1):23-33.

31. Wakelee $H$, Fisher GA: A phase I trial of irinotecan (CPT-11) with amifostine in patients with metastatic colorectal cancer. Investig New Drugs 2005, 23(3):241-242.

32. Delioukina ML, Prager D, Parson M, Hecht JR, Rosen P, Rosen LS: Phase II trial of irinotecan in combination with amifostine in patients with advanced colorectal carcinoma. Cancer 2002, 94(8):2174-2179. 
33. Lam W, Bussom S, Guan F, Jiang Z, Zhang W, Gullen EA, Liu SH, Cheng YC: The four-herb Chinese medicine PHY906 reduces chemotherapy-induced gastrointestinal toxicity. Sci Transl Med 2010, 2(45):45-59.

34. Farrell MP, Kummar S: Phase I/IIA randomized study of PHY906, a novel herbal agent, as a modulator of chemotherapy in patients with advanced colorectal cancer. Clin Colorectal Cancer 2003, 2(4):253-256.

35. Kummar S, Copur MS, Rose M, Wadler S, Stephenson J, O'Rourke M, Brenckman W, Tilton R, Liu SH, Jiang Z, Su T, Cheng YC, Chu E: A phase I study of the chinese herbal medicine PHY906 as a modulator of irinotecan-based chemotherapy in patients with advanced colorectal cancer. Clin Colorectal Cancer 2011, 10(2):85-96.

36. Yurkovetskiy L, Burrows $M$, Khan AA, Graham L, Volchkov P, Becker $L$, Antonopoulos D, Umesaki Y, Chervonsky AV: Gender bias in autoimmunity is influenced by microbiota. Immunity 2013, 39(2):400-412.

37. David LA, Maurice CF, Carmody RN, Gootenberg DB, Button JE, Wolfe BE, Ling AV, Devlin AS, Varma Y, Fischbach MA, Biddinger SB, Dutton RJ, Turnbaugh PJ: Diet rapidly and reproducibly alters the human gut microbiome. Nature 2014, 505(7484):559-563.

38. Hopkins MJ, Sharp R, Macfarlane GT: Age and disease related changes in intestinal bacterial populations assessed by cell culture, 16S rRNA abundance, and community cellular fatty acid profiles. Gut 2001, 48(2):198-205.

39. Kabeerdoss J, Sankaran V, Pugazhendhi S, Ramakrishna BS: Clostridium leptum group bacteria abundance and diversity in the fecal microbiota of patients with inflammatory bowel disease: a case-control study in India. BMC Gastroenterol 2013, 13:20.

40. Salzman NH, Hung K, Haribhai D, Chu H, Karlsson-Sjoberg J, Amir E, Teggatz P, Barman M, Hayward M, Eastwood D, Stoel M, Zhou Y, Sodergren E, Weinstock GM Bevins CL, Williams CB, Bos NA: Enteric defensins are essential regulators of intestinal microbial ecology. Nat Immunol 2010, 11(1):76-83.

41. Ngan LT, Moon JK, Kim JH, Shibamoto T, Ahn YJ: Growth-inhibiting effects of Paeonia lactiflora root steam distillate constituents and structurally related compounds on human intestinal bacteria. World J Microbiol Biotechnol 2012, 28(4):1575-1583.

42. Xing S, Wang M, Peng Y, Chen D, Li X: Simulated gastrointestinal tract metabolism and pharmacological activities of water extract of Scutellaria baicalensis roots. J Ethnopharmacol 2014, 152(1):183-189.

43. He J, Chen L, Heber D, Shi W, Lu QY: Antibacterial compounds from Glycyrrhiza uralensis. J Nat Prod 2006, 69(1):121-124.

44. Daneshmand F, Zare-Zardini H, Tolueinia B, Hasani Z, Ghanbari T: Crude Extract from Ziziphus Jujuba Fruits, a Weapon against Pediatric Infectious Disease. Iran J Pediatr Hematol Oncol 2013, 3(1):216-221.

45. Takasuna K, Hagiwara T, Hirohashi M, Kato M, Nomura M, Nagai E, Yokoi T, Kamataki T: Involvement of beta-glucuronidase in intestinal microflora in the intestinal toxicity of the antitumor camptothecin derivative irinotecan hydrochloride (CPT-11) in rats. Cancer Res 1996, 56(16):3752-3757.

46. Zhang W, Saif MW, Dutschman GE, Li X, Lam W, Bussom S, Jiang Z, Ye M, Chu E, Cheng YC: Identification of chemicals and their metabolites from PHY906, a Chinese medicine formulation, in the plasma of a patient treated with irinotecan and PHY906 using liquid chromatography/tandem mass spectrometry (LC/MS/MS). J Chromatogr A 2010, 1217(37):5785-5793.

47. Johansson ME, Phillipson M, Petersson J, Velcich A, Holm L, Hansson GC: The inner of the two Muc2 mucin-dependent mucus layers in colon is devoid of bacteria. Proc Natl Acad Sci U S A 2008, 105(39):15064-15069.

48. Velcich A, Yang W, Heyer J, Fragale A, Nicholas C, Viani S, Kucherlapati R, Lipkin M, Yang K, Augenlicht L: Colorectal cancer in mice genetically deficient in the mucin Muc2. Science 2002, 295(5560):1726-1729.

49. Van der Sluis M, De Koning BA, De Bruijn AC, Velcich A, Meijerink JP, Van Goudoever JB, Buller HA, Dekker J, Van Seuningen I, Renes IB, Einerhand AW: Muc2-deficient mice spontaneously develop colitis, indicating that MUC2 is critical for colonic protection. Gastroenterology 2006, 131(1):117-129.

50. Sato T, Vries RG, Snippert HJ, van de Wetering M, Barker N, Stange DE, van Es JH, Abo A, Kujala P, Peters PJ, Clevers H: Single Lgr5 stem cells build crypt-villus structures in vitro without a mesenchymal niche. Nature 2009, 459(7244):262-265.

51. Barker $\mathrm{N}$, van Es JH, Kuipers J, Kujala P, van den Born M, Cozijnsen M, Haegebarth A, Korving J, Begthel H, Peters PJ, Clevers H: Identification of stem cells in small intestine and colon by marker gene Lgr5. Nature 2007, 449(7165):1003-1007.
52. van der Flier $L G$, van Gijn ME, Hatzis $P$, Kujala $P$, Haegebarth $A$, Stange DE, Begthel H, van den Born M, Guryev V, Oving I, van Es JH, Barker N, Peters PJ, van de Wetering M, Clevers $\mathrm{H}$ : Transcription factor achaete scute-like 2 controls intestinal stem cell fate. Cell 2009, 136(5):903-912.

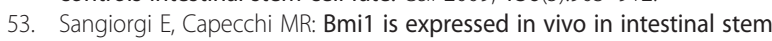
cells. Nat Genet 2008, 40(7):915-920.

54. Buchon N, Broderick NA, Chakrabarti S, Lemaitre B: Invasive and indigenous microbiota impact intestinal stem cell activity through multiple pathways in Drosophila. Genes Dev 2009, 23(19):2333-2344.

55. Atreya I, Atreya R, Neurath MF: NF-kappaB in inflammatory bowel disease. J Intern Med 2008, 263(6):591-596.

56. Park YS: COX-2 inhibitors in inflammatory bowel disease: friends or foes? Korean J Gastroenterol 2007, 50(6):350-355.

57. Kolios G, Valatas V, Ward SG: Nitric oxide in inflammatory bowel disease: a universal messenger in an unsolved puzzle. Immunology 2004, 113(4):427-437.

\section{doi:10.1186/1472-6882-14-490}

Cite this article as: Lam et al:: The number of intestinal bacteria is not critical for the enhancement of antitumor activity and reduction of intestinal toxicity of irinotecan by the Chinese herbal medicine PHY906 (KD018). BMC Complementary and Alternative Medicine 2014 14:490.

\section{Submit your next manuscript to BioMed Central and take full advantage of:}

- Convenient online submission

- Thorough peer review

- No space constraints or color figure charges

- Immediate publication on acceptance

- Inclusion in PubMed, CAS, Scopus and Google Scholar

- Research which is freely available for redistribution

Submit your manuscript at www.biomedcentral.com/submit
() Biomed Central 